July 1999 • NREL/TP-560-26483

\title{
Calculating the Diffuse Responsivity of Solar Pyranometers
}

I. Reda and D. Myers

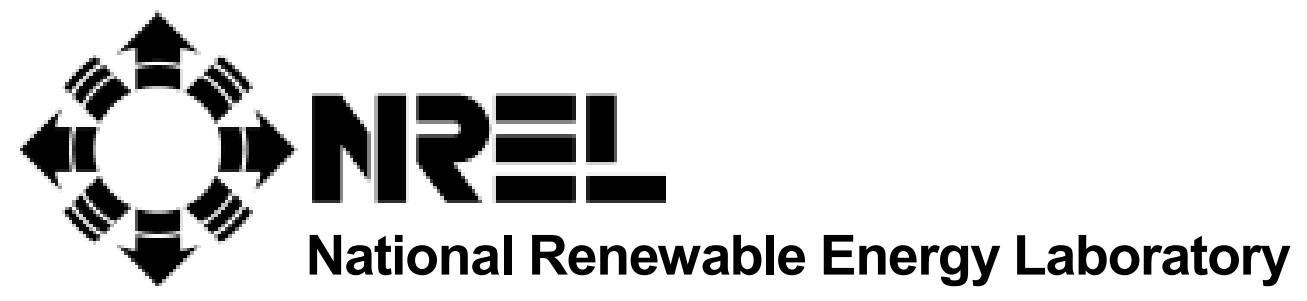

1617 Cole Boulevard

Golden, Colorado 80401-3393

NREL is a U.S. Department of Energy Laboratory

Operated by Midwest Research Institute • Battelle • Bechtel

Contract No. DE-AC36-98-G010337 


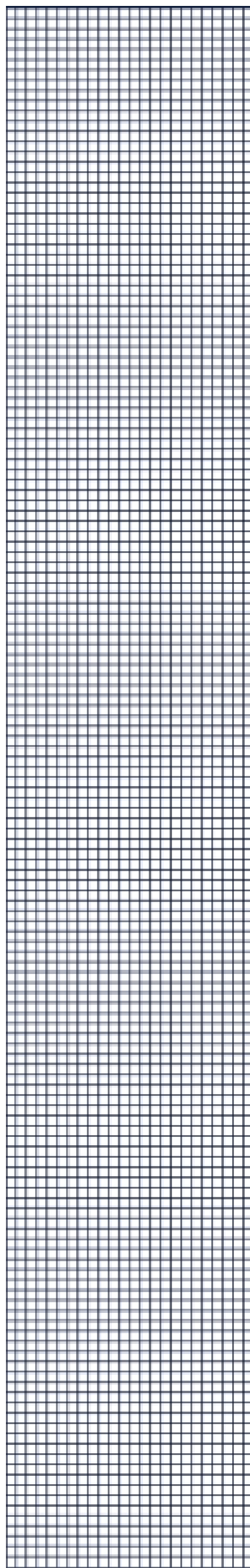

July 1999 • NREL/TP-560-26483

\title{
Calculating the Diffusive Responsivity of Solar Pyranometers
}

\author{
I. Reda and D. Myers
}

Prepared under Task No. 5600.2010

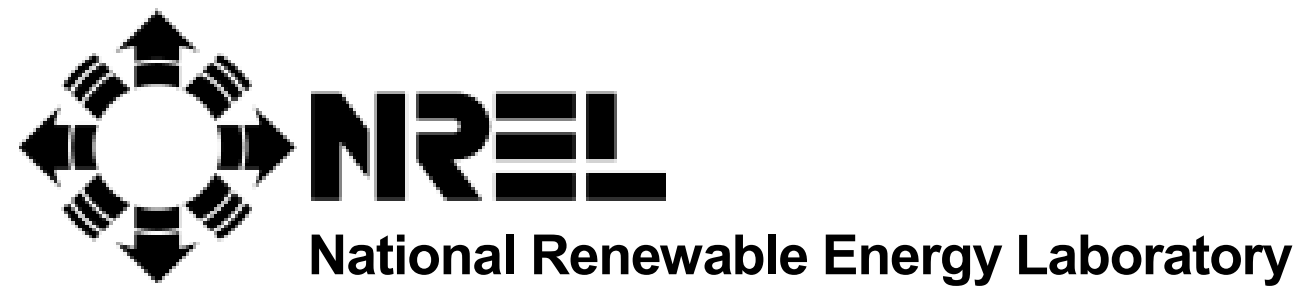

1617 Cole Boulevard

Golden, Colorado 80401-3393

NREL is a U.S. Department of Energy Laboratory

Operated by Midwest Research Institute • Battelle • Bechtel

Contract No. DE-AC36-98-G010337 


\section{NOTICE}

This report was prepared as an account of work sponsored by an agency of the United States government. Neither the United States government nor any agency thereof, nor any of their employees, makes any warranty, express or implied, or assumes any legal liability or responsibility for the accuracy, completeness, or usefulness of any information, apparatus, product, or process disclosed, or represents that its use would not infringe privately owned rights. Reference herein to any specific commercial product, process, or service by trade name, trademark, manufacturer, or otherwise does not necessarily constitute or imply its endorsement, recommendation, or favoring by the United States government or any agency thereof. The views and opinions of authors expressed herein do not necessarily state or reflect those of the United States government or any agency thereof.

Available to DOE and DOE contractors from:

Office of Scientific and Technical Information (OSTI)

P.O. Box 62

Oak Ridge, TN 37831

Prices available by calling 423-576-8401

Available to the public from:

National Technical Information Service (NTIS)

U.S. Department of Commerce

5285 Port Royal Road

Springfield, VA 22161

$703-605-6000$ or $800-553-6847$

or

DOE Information Bridge

http://www.doe.gov/bridge/home.html

Printed on paper containing at least $50 \%$ wastepaper, including $20 \%$ postconsumer waste 


\section{Abstract}

Pyranometers are used to measure the global and diffuse components of solar irradiance. One of the methods to calculate the unshade (global) responsivity of a pyranometer, is the standard shading method, described in the Annual Book of ASTM Standards, section 14, volume 14.02. In this paper, the standard method is used to calculate the shade (diffuse) responsivity of a pyranometer by accounting for the zenith and azimuth response of the pyranometer. A discussion of the effect of pyranometer offset on the calculated responsivity is also presented. 


\section{Table of Contents}

\section{Chapters}

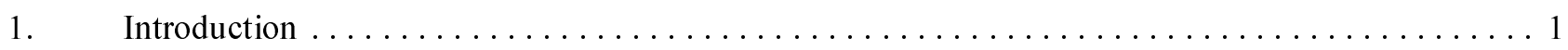

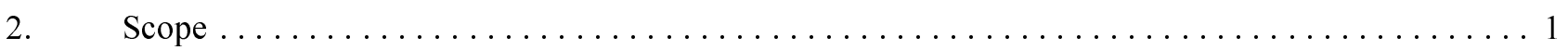

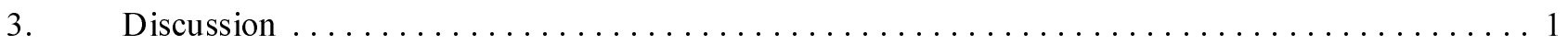

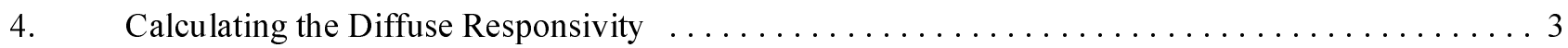

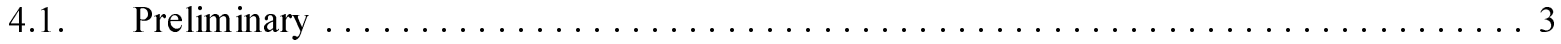

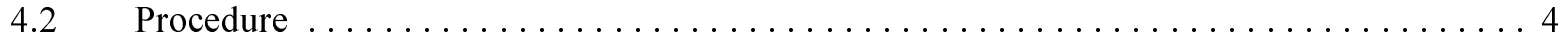

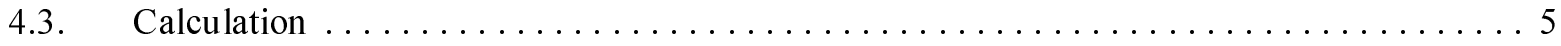

4.4. Pyranometer Offset Discussion on the Shade/Unshade Method $\ldots \ldots \ldots \ldots \ldots \ldots \ldots \ldots$

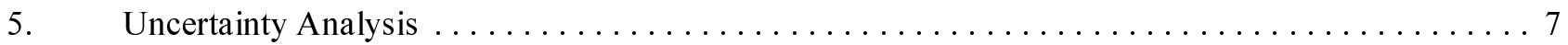

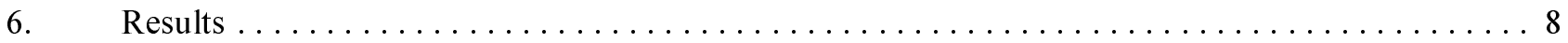

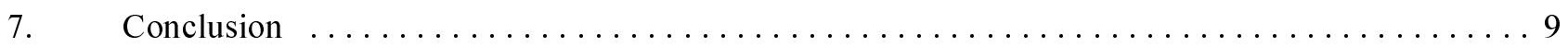

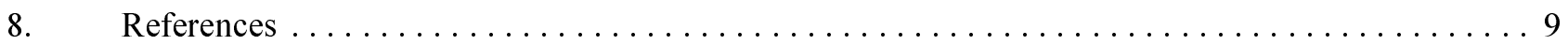

Figures

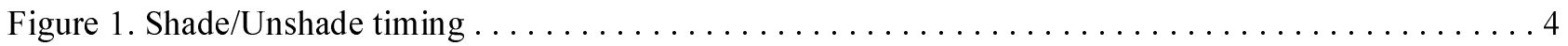

\section{Tables}

Table 1. Summary Results of PSP, Serial Number $20715 \mathrm{~F} 3 \ldots \ldots \ldots \ldots \ldots \ldots \ldots \ldots \ldots$ 


\section{Introduction}

Pyranometers are used to measure the global and diffuse components of solar irradiance. Accurate and precise measurement of the global or diffuse irradiance is dependant on the method of calculating the pyranometer's unshade (global) or shade (diffuse) responsivity. One of the recognized methods to calculate the unshade responsivity is the standard shading method, described in the Annual Book of ASTM Standards [1]. In this paper, the diffuse responsivity of a pyranometer is calculated by using the shade/unshade timing and sky conditions, described in the ASTM procedure, with an exception that the number of cycles of the shade/unshade are reduced and the pyranometer is horizontally rotated, in $120^{\circ}$ increments, to account for the geometry and azimuth response of the pyranometer's sensor. A discussion of the pyranometer offset effect on the calculated responsivity and uncertainty is presented. The results of a selected pyranometer are also presented in a later chapter.

\section{Scope}

It is suggested that Kimball recommended the shade/unshade method in the early 1900s [2]. Until now, this method has been used worldwide to calculate the responsivity of unshaded pyranometers using the following procedure:

1. Shade the pyranometer under test (PUT), then record its output voltage $\left(\mathrm{V}_{\mathrm{s}}\right)$, in $\mu \mathrm{V}$.

2. Unshade the PUT, then record the beam irradiance $\left(B_{u}\right)$, the solar zenith angle $\left(\theta_{u}\right)$, and the PUT's output voltage $\left(\mathrm{V}_{\mathrm{u}}\right)$, in $\mathrm{W} / \mathrm{m}^{2}$, degrees, and $\mu \mathrm{V}$, respectively.

3. Calculate the Responsivity (RS),

$$
R S=\frac{V_{u}-V_{s}}{B_{u} * \operatorname{COS}\left(\theta_{u}\right)} .
$$

The shade/unshade timing sequence, the instruments required, and the sky conditions are described in the Annual Book of ASTM Standards[1]. The same procedure is adopted in this paper to calculate the shade (diffuse) responsivity of a pyranometer.

\section{Discussion}

The diffuse responsivity, $\mathrm{RS}_{\mathrm{d}}$, for a diffuse irradiance distribution, $\mathrm{D}(\theta, \phi)$, and pyranometer's responsivity, $\operatorname{RS}(\theta)$, is calculated using Equation 3.1 [2],

$$
R S_{d}=\frac{\int_{0}^{2 \pi} \int_{0}^{\frac{\pi}{2}} R S(\theta) * D(\theta, \phi) * \operatorname{Sin}(2 \theta) \cdot d \theta d \phi}{\int_{0}^{2 \pi} \int_{0}^{\frac{\pi}{2}} D(\theta, \phi) * \operatorname{Sin}(2 \theta) \cdot d \theta d \phi},
$$


where, $\theta$ and $\phi$ are the zenith and azimuth angles, respectively.

From many pyranometer calibrations, it has been proven that the responsivity of a pyranometer is a function of $\theta$ and $\phi[3]$. Thus Equation 3.1 is rewritten as,

$$
R S_{d}=\frac{\int_{0}^{2 \pi} \int_{0}^{\frac{\pi}{2}} R S(\theta, \phi) * D(\theta, \phi) * \operatorname{Sin}(2 \theta) \cdot d \theta d \phi}{\int_{0}^{2 \pi} \int_{0}^{\frac{\pi}{2}} D(\theta, \phi) * \operatorname{Sin}(2 \theta) \cdot d \theta d \phi} .
$$

where, $\operatorname{RS}(\theta, \phi)$ is determined by using the standard shading method, or any recognized calibration method.

From equation 3.2, one can notice that $\mathrm{RS}_{\mathrm{d}}$ will change in value with the change of the diffuse irradiance distribution, $\mathrm{D}(\theta, \phi)$. Because the diffuse irradiance distribution is ever changing, depending on the sky conditions and cloud distribution, it is difficult to calculate $\mathrm{RS}_{\mathrm{d}}$, although its value will always lie between the extreme values of $\operatorname{RS}(\theta, \phi)$.

Thus, for all sky conditions, $\mathrm{RS}_{\mathrm{d}}$ can be considered as,

$$
R S_{d}=\frac{R S_{\max }(\theta, \phi)+R S_{\min }(\theta, \phi)}{2},
$$

and, its percentage uncertainty, $\mathrm{U}_{\mathrm{d}}$, can be considered as,

$$
U_{d}= \pm \frac{\left[R S_{\max }(\theta, \phi)-R S_{\min }(\theta, \phi)\right] * 100}{2 * R S_{d}}
$$

where, $\operatorname{RS}_{\max }(\theta, \phi)$ and $\mathrm{RS}_{\min }(\theta, \phi)$ are the maximum and minimum responsivities of the pyranometer.

Yet, for the clear sky condition, where the diffuse distribution is approximately uniform, $\mathrm{RS}_{\mathrm{d}}$ will equal to the responsivity at $\theta$ equals approximately $45^{\circ}$. Thus for the clear sky condition, $\mathrm{RS}_{\mathrm{d}}$ is,

$$
R S_{d}=\int_{0}^{2 \pi} R S\left(45^{\circ}, \phi\right) \cdot d \phi,
$$

A reasonable assumption is that $\mathrm{RS}_{\mathrm{d}}$ will equal to the responsivity in the range from $\operatorname{RS}\left(30^{\circ}, \phi\right)$ to $\operatorname{RS}\left(60^{\circ}\right.$, $\phi)$. The zenith angle range from $30^{\circ}$ to $60^{\circ}$ is believed to account for the non-uniformity in the diffuse distribution during any clear sky condition. From this assumption, $\operatorname{RS}_{\max }(\theta, \phi)$ and $\operatorname{RS}_{\min }(\theta, \phi)$ can be calculated in the solar zenith angle range from $30^{\circ}$ to $60^{\circ}$ which will result in smaller uncertainty, using Equation 3.4, than the all sky condition uncertainty. The uncertainty values of all sky conditions and the clear sky condition are shown in Table 1 in the Results Chapter. 


\section{Calculating the Diffuse Responsivity}

The first step in calculating the diffuse responsivity is to determine $\operatorname{RS}(\theta, \phi)$ for the PUT, using the standard shading method or any recognized method. Then, for all sky conditions, $\mathrm{RS}_{\mathrm{d}}$ and $\mathrm{U}_{\mathrm{d}}$ can easily be calculated using Equations 3.3 and 3.4.

For the clear sky condition, the ideal method to calculate $\mathrm{RS}_{\mathrm{d}}$, using Equation 3.5, is to calculate all responsivities, $\mathrm{RS}_{45, \phi}$, at small increments of $\phi$, from $0^{\circ}$ to $360^{\circ}$. The ideal method requires many calibrations outdoor under clear sky conditions, which is a difficult task for the majority of pyranometer users. A practical method is to rotate the test pyranometer horizontal from its original position at $0^{\circ}$ to $120^{\circ}$ then $240^{\circ}$. The original position, typically, is where the pyranometer's signal connector is oriented towards the opposite side of the equator (for example, it is oriented towards the north in the northern hemisphere). The responsivities for the three positions, $\mathrm{RS}_{0}, \mathrm{RS}_{120}$, and $\mathrm{RS}_{240}$ are then calculated. $\mathrm{RS}_{0}, \mathrm{RS}_{120}$, and $\mathrm{RS}_{240}$ can be calculated by performing the procedure in three clear sky days at $\theta$ equals $45^{\circ}\left( \pm 0.5^{\circ}\right)$, one day for each horizontal position, $0^{\circ}, 120^{\circ}$, and $240^{\circ}$, or it can be accomplished, for the three horizontal positions, in one clear day at $\theta$ equals $45^{\circ}\left( \pm 2^{\circ}\right)$. The change of responsivity, within the $\pm 0.5^{\circ}$ or the $\pm 2^{\circ}$ zenith angle range, is then considered as an uncertainty $\left(\mathrm{U}_{\Delta \theta}\right)$. This uncertainty is then added to the total uncertainty as described in the Uncertainty Analysis Chapter.

The average of the three responsivities, $\mathrm{RS}_{0}, \mathrm{RS}_{120}$, and $\mathrm{RS}_{240}$ is calculated. This is the diffuse responsivity for this set. Then the procedure is repeated for several days to account for the spectral response and the sensor geometry of the pyranometer, then the average of all the diffuse responsivities from all sets is considered the diffuse responsivity, $\mathrm{RS}_{\mathrm{d}}$, of the PUT.

The following procedure is a summary of calculating the diffuse responsivity for a solar pyranometer for clear sky conditions using the one day technique. For the three days technique, the same procedure is used with the exception that it is performed on one day for each horizontal position, $0^{\circ}, 120^{\circ}$, and $240^{\circ}$.

\subsection{Preliminary}

1. Determine $\operatorname{RS}(\theta, \phi)$ for the PUT, using the standard shading method or any recognized method.

2. The procedure is performed under clear sky conditions, as described in the Annual Book of ASTM Standards, section 14, volume 14.02. A pyrheliometer is used to measure the direct normal (beam) solar irradiance. An absolute cavity radiometer with traceability to the world radiometric reference (WRR) is recommended.

3. The PUT is installed outdoor, horizontally leveled using the spirit bubble level in the pyranometer base, and the signal connector is oriented towards the opposite side of the equator. This is position $0^{\circ}$. To allow the PUT to reach thermal equilibrium with the environment, it is installed, unshaded, 30minutes before starting the procedure. This is the preliminary soaking period, A [1].

4. Start the procedure after the A period and when $\theta$ equals approximately $43^{\circ}$.

5. Figure 1 shows the shade/unshade timing sequence, where $\mathrm{A}$ is the unshaded preconditioning soak period, B is equal to 20 to 30 times the PUT time constants, $\mathrm{C}$ is equal to 60 times the PUT time constants, and $\mathrm{M}$ is a period of 30 seconds when the data is collected [1]. 


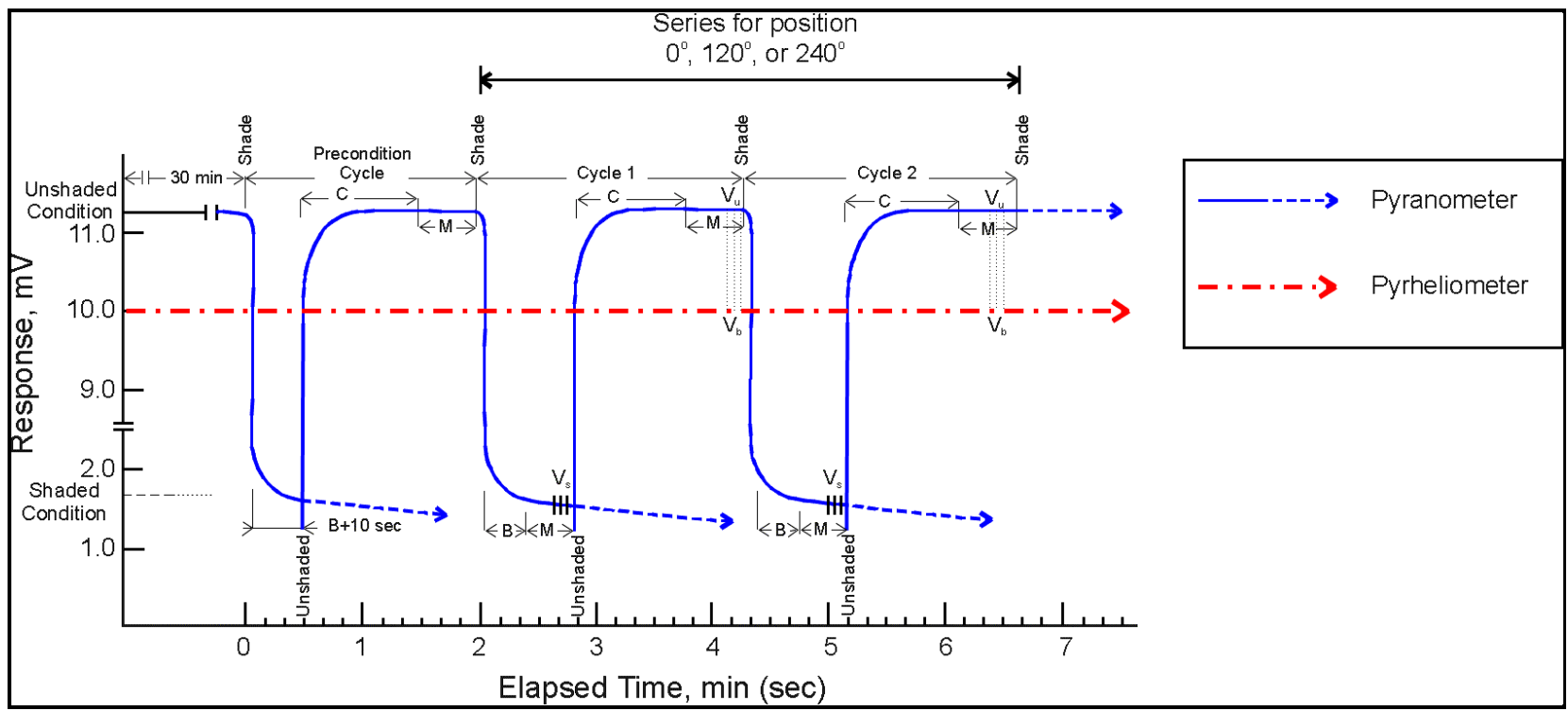

Figure 1. Shade/Unshade timing.

\subsection{Procedure}

Refer to figure 1 for timing and nomenclature.

1. Shade the PUT for the period B, then unshade the PUT for a period $\mathrm{C}+\mathrm{M}$. This is the reconditioning cycle.

2. Shade the PUT for a period B, then, during the period M, collect at least three instantaneous readings of the output voltage of the PUT, in $\mu \mathrm{V}$.

Record the calculated average of the output voltage, $\mathrm{V}_{\mathrm{s}, 1,0}$,

$$
V_{s, 1,0}=\sum_{i=0}^{n} \frac{V_{s, 1,0, i}}{n}
$$

where:

- 1 refers to the shade/unshade cycle number 1

- 0 refers to the pyranometer horizontal position at $0^{\circ}$

- $\mathrm{i}$ is the $\mathrm{i}^{\text {th }}$ reading

- $\mathrm{n}$ is the number of instantaneous readings.

3. Unshade the PUT for the period C, then, during the period M, collect at least three instantaneous readings of the output voltages of the PUT and the pyrheliometer. Using the pyrheliometer instructions, calculate the beam irradiance from its output voltage, $\mathrm{V}_{\mathrm{b}}$. Calculate the solar zenith angle at each instantaneous reading, then, using Equation 4.1, calculate and record the calculated averages of the output voltages of the PUT $\left(\mathrm{V}_{\mathrm{u}, 1,0}\right)$, the beam irradiances $\left(\mathrm{B}_{\mathrm{u}, 1,0}\right)$, and the solar zenith angles $\left(\theta_{\mathrm{u}, 1,0}\right)$. 
4. Repeat steps 2 and 3 for the shade/unshade cycle number 2, and record $\mathrm{V}_{\mathrm{s}, 2,0}, \mathrm{~V}_{\mathrm{u}, 2,0}, \mathrm{~B}_{\mathrm{u}, 2,0}$, and $\theta_{\mathrm{u}, 2,0}$.

5. After cycle number 2 is ended, rotate the pyranometer, horizontally, $120^{\circ}$, clockwise from the previous position, and re-level it horizontally using the spirit bubble level.

6. Wait 3 minutes for thermal equilibrium, then repeat steps 1 through 5 for positions $120^{\circ}$, and $240^{\circ}$.

\subsection{Calculation}

1. Calculate the responsivity of the PUT at cycle number 1 and horizontal position $0^{\circ}, \mathrm{RS}_{1,0}$,

$$
R S_{1,0}=\frac{V_{u, 1,0}-V_{s, 1,0}}{B_{u, 1,0} * \operatorname{COS}\left(\theta_{u, 1,0}\right)},
$$

2. Repeat step 1 to calculate the responsivity of the PUT at cycle number 2 and horizontal position $0^{\circ}, \mathrm{RS}_{2,0}$.

3. Calculate the responsivity at the horizontal position $0^{\circ}, \mathrm{RS}_{0}$,

$$
R S_{0}=\frac{R S_{1,0}+R S_{2,0}}{2}
$$

4. Repeat steps 1 through 3 to calculate the responsivities $\mathrm{RS}_{120}$, and $\mathrm{RS}_{240}$ at the horizontal positions $120^{\circ}$, and $240^{\circ}$, respectively.

5. Calculate the diffuse responsivity, $\mathrm{RS}_{\mathrm{d}, \mathrm{k}}$,

$$
R S_{d, k}=\frac{R S_{0}+R S_{120}+R S_{240}}{3},
$$

where, $\mathrm{k}$ is the $\mathrm{k}^{\text {th }}$ day, when $\mathrm{RS}_{0}, \mathrm{RS}_{120}, \mathrm{RS}_{240}$ are calculated.

6. Repeat the procedure described in this chapter over a sufficient number of days throughout the year to account for the change of responsivity with the solar azimuth angle $(\phi)$, then calculate the average of all calculated diffuse responsivities. This will be the diffuse responsivity of the PUT $\left(\mathrm{RS}_{\mathrm{d}}\right)$ for the clear sky condition,

$$
R S_{d}=\frac{\sum_{k=0}^{z} R S_{d, k}}{z}
$$

where, $\mathrm{z}$ is the number of days when the procedure is performed. 
7. Calculate the standard deviation of $\mathrm{RS}_{\mathrm{d}}, \mathrm{SD}$,

$$
S D=\sqrt{\frac{\sum_{k=0}^{z}\left(R S_{d, k}-R S_{d}\right)^{2}}{z-1}} .
$$

\subsection{Pyranometer Offset Discussion on the Shade/Unshade Method}

It has been observed that thermopile pyranometers measure offset radiation when there is no short-wave radiation or at solar zenith angles greater than $90^{\circ}$ (night-time offset)[4]. This offset radiation is thought to be attributed to the long-wave radiation measured by the pyranometer and the thermal gradient between the hot and reference junction of the pyranometer thermopile. The following discusses the effect of the offset on the calculated diffuse responsivity of a pyranometer:

Accounting for the offset signals in Equation 4.2 will yield,

$$
R S_{1,0}=\left(\frac{\left.V_{u, 1,0}-v_{u, 1,0}\right)-\left(V_{s, 1,0}-v_{s, 1,0}\right)}{B_{u, 1,0} * \operatorname{COS}\left(\theta_{u, 1,0}\right)}=\frac{V_{u, 1,0}-V_{s, 1,0}-\Delta v}{B_{u, 1,0} * \operatorname{COS}\left(\theta_{u, 1,0}\right)},\right.
$$

and,

$$
\Delta v=v_{u, 1,0}-v_{s, 1,0}
$$

where:

- $\mathrm{v}_{\mathrm{u}, 1,0}$ is the offset output voltage, in $\mu \mathrm{V}$, of the PUT during the unshade-period of cycle 1

- $\mathrm{v}_{\mathrm{s}, 1,0}$ is the offset output voltage, in $\mu \mathrm{V}$, of the PUT during the shade-period of cycle 1

By using the shade/unshade soaking period and timing sequence, described in the Annual Book of ASTM Standards[1], the pyranometer's thermodynamics during the unshade-period is believed to be the same during the shade-period. From this assumption, the value of $\mathrm{v}_{\mathrm{u}, 1,0}$ will approximately equal the value of $\mathrm{v}_{\mathrm{s}, 1,0}$ which will cause the term $\Delta \mathrm{v}$ to be approximately zero. Yet $\Delta \mathrm{v}$ can be estimated for different types of pyranometers. The percentage uncertainty resulting from the pyranometer offset, $\mathrm{U}_{\text {off }}$, is calculated as,

$$
U_{o f f}= \pm \frac{\Delta v * 100}{V_{u, 1,0}-V_{s, 1,0}}
$$

Table 1, in the Results Chapter, shows the magnitude of $\mathrm{U}_{\text {off }}$ for EPLAB pyranometer model PSP, with the assumption that $\Delta \mathrm{v}$ is in the range from $-20 \mu \mathrm{V}$ to $+20 \mu \mathrm{V}$. 


\section{Uncertainty Analysis}

To calculate the total uncertainty of $\mathrm{RS}_{\mathrm{d}}$, this procedure is used:

1. Calculate the total percentage uncertainty of the measuring process, $\mathrm{U}_{\mathrm{m}}$,

$$
U_{m}= \pm \sqrt{\left(U_{p y r}\right)^{2}+\left(U_{D A Q}\right)^{2}+\left(U_{\theta}\right)^{2}+\left(U_{\Delta \theta}\right)^{2}+\left(U_{o f f}\right)^{2}},
$$

where:

- $\mathrm{U}_{\mathrm{pyr}}$ is the uncertainty of the pyrheliometer, in percentage

- $\mathrm{U}_{\mathrm{DAQ}}$ is the uncertainty of the data acquisition system, in percentage

- $\mathrm{U}_{\theta}$ is the uncertainty of the solar zenith angle calculation, in percentage

- $\mathrm{U}_{\Delta \theta}$ is the uncertainty resulting from the change of responsivity during the procedure, in percentage. From $\operatorname{RS}(\theta, \phi)$, determine $\operatorname{RS}_{\max }(\theta, \phi)$ and $\operatorname{RS}_{\min }(\theta, \phi)$ during the range of $\theta$, where the procedure is performed, then use the right hand side of Equation 3.4 to calculate $\mathrm{U}_{\Delta \theta}$.

2. From $\operatorname{RS}(\theta, \phi)$, determine the extremes and use equation 3.4 to calculate $U_{d}$. The extremes are determined from the applicable range of $\theta$. For measuring the diffuse under all sky conditions the applicable range of $\theta$ is from $0^{\circ}$ to $90^{\circ}$. For measuring the diffuse under clear sky conditions, the applicable range of $\theta$ is from $30^{\circ}$ to $60^{\circ}$.

3. Calculate the total uncertainty, $\mathrm{U}_{95}$, of the diffuse responsivity of the PUT,

$$
U_{95}= \pm \sqrt{\left(U_{m}\right)^{2}+\left(U_{d}\right)^{2}+(t * S D)^{2}},
$$

where, $t$ is Student's "t". $t$ equals 12.706, 4.303, and 3.182 for sample sizes 2, 3, and 4, respectively, and approximately 2 for sample sizes greater than 21 [5]. 


\section{Results}

A Ventilated PUT (serial numbers 20715F3), and an absolute cavity radiometer (serial number AHF31104) were used. The PUT was ventilated to minimize the temperature gradient between the hot and reference junction of its thermopile. The procedure was performed on 4/13/1999,5/18/1999, and 5/19/1999. Table 1 shows that $\mathrm{RS}_{\mathrm{d}}$ is equal to $10.15 \mu \mathrm{V} / \mathrm{W} / \mathrm{m}^{2}$, and $\mathrm{U}_{95}$ equals $\pm 6.42 \%$, for all sky conditions, and $\mathrm{RS}_{\mathrm{d}}$ is equal to $10.305 \mu \mathrm{V} / \mathrm{W} / \mathrm{m}^{2}$, and $\mathrm{U}_{95}$ equals $\pm 2.52 \%$, for the clear sky condition.

Table 1. Summary Results of PSP, Serial Number 20715F3

\begin{tabular}{|c|c|c|}
\hline & All Sky Conditions & Clear Sky Condition \\
\hline \hline 1. Responsivity & & \\
\hline $\mathrm{RS}_{45,0}$ & & $10.376 \mu \mathrm{V} / \mathrm{W} / \mathrm{m}^{2}$ \\
\hline $\mathrm{RS}_{45,120}$ & & $10.283 \mu \mathrm{V} / \mathrm{W} / \mathrm{m}^{2}$ \\
\hline $\mathrm{RS}_{45,240}$ & & $10.257 \mu \mathrm{V} / \mathrm{V} / \mathrm{m}^{2}$ \\
\hline $\mathrm{RS}_{\mathrm{d}}$ & $10.15 \mu \mathrm{V} / \mathrm{W} / \mathrm{m}^{2}$ & $10.305 \mu \mathrm{V} / \mathrm{W} / \mathrm{m}^{2}$ \\
\hline $\mathrm{U}_{\mathrm{pyr}}{ }^{(1)}$ & & \\
\hline $\mathrm{U}_{\mathrm{DAQ}}{ }^{(2)}$ & $\pm 0.40 \%$ & $\pm 0.40 \%$ \\
\hline $\mathrm{U}_{\theta}{ }^{(3)}$ & $\pm 0.01 \%$ & $\pm 0.01 \%$ \\
\hline $\mathrm{U}_{\text {off }}$ & $\pm 0.02 \%$ & $\pm 0.02 \%$ \\
\hline $\mathrm{U}_{\Delta \theta}{ }^{(4)}$ & $\pm 0.32 \%$ & $\pm 0.32 \%$ \\
\hline $\mathrm{U}_{\mathrm{m}}$ & & $\pm 0.50 \%$ \\
\hline $\mathrm{U}_{\mathrm{d}}{ }^{(4)}$ & & $\pm 0.72 \%$ \\
\hline $\mathrm{t}^{(5)}$ & $\pm 6.40 \%$ & $\pm 1.50 \%$ \\
\hline $\mathrm{SD}^{(5)}$ & & 4.3 \\
\hline $\mathrm{U}_{95}$ & & $\pm 0.44 \%$ \\
\hline
\end{tabular}

(1) from reference number 6, (2) from the data acquisition manual (Model hp34970A), (3) from reference number 7, (4) from reference number 3, and (5) from reference number 5 . 


\section{Conclusion}

1. Performing this procedure in many days throughout the year will account for the spectral response and sensor geometry of the PUT.

2. To measure the diffuse irradiance with the calculated uncertainties, the PUT must be corrected for its offset. A method to correct for the pyranometer offset is described in reference number 8 in the References Chapter.

4. From Table 1, one can notice that $U_{d}$ is the dominant value in the calculated total uncertainty. From this, choosing pyranometers with radiometrically leveled sensors can achieve lower uncertainties.

5. The reported uncertainties in Table 1 are the uncertainties of the calculated diffuse responsivity. Other uncertainties resulting from the pyranometer setup and data acquisition system used to collect the diffuse data are added by the user.

\section{References}

1. Annual Book of ASTM Standards Vol. 14.02, Sec. 14, pp. 592-598, USA.

2. $\quad$ Forgan, B.W., The Measurement of Solar Irradiance: Instrumentation and Measurements in the Adelaide Region, 1979, pp. 45-86.

3. National Renewable Energy Laboratory (NREL), NREL BORCAL Reports, Golden, Colorado, USA.

4. Gulbrandsen, A. "on the use of pyranometers in the study of spectral solar radiation and atmospheric aerosols" Journal of Applied Meteorology, Vol. 4 pp 1-16, 1960.

5. Dieck, R. H. (Copy right 1992, second printing January 1995), Measurement Uncertainty: Methods and Applications, North Carolina, Instrument Society of America, p.15.

6. WRC/PMOD, 1996. International Pyrheliometer Comparison, IPC VIII, 25 September - 13 October 1995, Results and Symposium. Working Report No. 188, Swiss Meteorological Institute, Dorfstrasse 33, CH-7260 Davos Dorf, Switzerland, 115 pp.

7. Solar Energy Vol. 40, No. 3, pp. 227-235, 1988, USA. 


\section{REPORT DOCUMENTATION PAGE}

Form Approved

OMB NO. 0704-0188

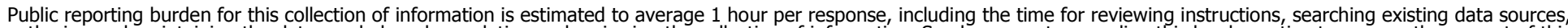

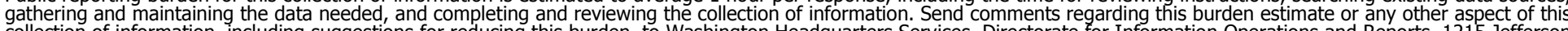

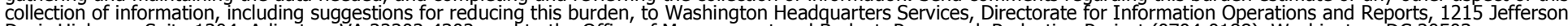

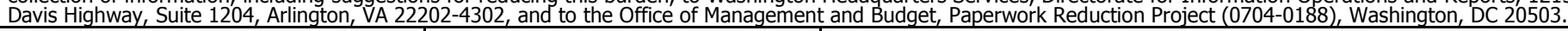

\begin{tabular}{|l|l|l}
\hline 1. AGENCY USE ONLY (Leave blank) & $\begin{array}{c}\text { 2. REPORT DATE } \\
\text { July } 1999\end{array}$ & $\begin{array}{l}\text { 3. REPORT TYPE AND DATES COVERED } \\
\text { Technical report: } 1999\end{array}$ \\
\hline
\end{tabular}

4. TITLE AND SUBTITLE

Calculating the Diffuse Responsivity of Solar Pyranometers

6. AUTHOR(S)

Ibrahim Reda and Daryl Myers

7. PERFORMING ORGANIZATION NAME(S) AND ADDRESS(ES)
5. FUNDING NUMBERS

5600.2010

8. PERFORMING ORGANIZATION REPORT NUMBER

10. SPONSORING/MONITORING AGENCY REPORT NUMBER

TP-560-26483

1617 Cole Blvd.

Golden, CO 80401-3393

ADDRESS(ES)

SPONSORING/MONITORING AGENCY NAME(S) AND
National Renewable Energy Laboratory

11. SUPPLEMENTARY NOTES

NREL Technical Monitor:

12a. DISTRIBUTION/AVAILABILITY STATEMENT

National Technical Information Service

12b. DISTRIBUTION CODE

U.S. Department of Commerce

5285 Port Royal Road

Springfield, VA 22161

13. ABSTRACT (Maximum 200 words)

Pyranometers are used to measure the global and diffuse components of solar irradiance. One of the methods to calculate the unshade (global) responsivity of a pyranometer is the standard shading method, described in the Annual Book of ASTM Standards, section 14, volume 14.02. In this paper, the standard method is used to calculate the shade (diffuse) responsivity of a pyranometer by accounting for the zenith and azimuth response of the pyranometer. A discussion of the effect of pyranometer offset on the calculated responsivity is also presented.

\begin{tabular}{|c|c|c|c|}
\hline \multicolumn{3}{|l|}{ 14. SUBJECT TERMS } & $\begin{array}{l}\text { 15. NUMBER OF PAGES } \\
10\end{array}$ \\
\hline $\begin{array}{l}\text { 17. SECURITY CLASSIFICATION } \\
\text { OF REPORT }\end{array}$ & $\begin{array}{l}\text { 18. SECURITY CLASSIFICATION } \\
\text { OF THIS PAGE }\end{array}$ & $\begin{array}{l}\text { 19. SECURITY CLASSIFICATION } \\
\text { OF ABSTRACT }\end{array}$ & 20. LIMITATION OF ABSTRACT \\
\hline
\end{tabular}

NSN 7540-01-280-5500

Standard Form 298 (Rev. 2-89) Prescribed by ANSI Std. Z39-18 